\section{Muscle receptors}

Muscle Receptors. (Handbook of Sensory Physiology, Volume 3, Part 2.) Edited by C. C. Hunt. Pp. viii +312 . (Springer: Berlin and New York, 1974.) DM104; $\$ 42.50$.

THIs volume is made up of three different sections, each by a different author. A long (190 pages) section by Barker on the anatomy of muscle receptors is followed by much shorter sections on their physiology (Hunt) and central actions (McIntyre).

The anatomical section is a very full review of the present state of the subject with numerous illustrations and a comprehensive bibliography; it fills a real need and it will serve as a valuable reference book. The greater part of this section deals with muscle spindles, although other receptors are also very adequately treated. Many aspects of muscle spindle anatomy and its relationship to function remain controversial-and here Barker's own views come across quite clearly-although he takes care to mention the points of disagreement.

In the other two sections of this volume the authors have been in some difficulty: Matthews' very full account of the properties of mammalian muscle receptors appeared only two years earlier, and there was clearly no need for another comprehensive review.

Hunt deals briefly with many of the properties of muscle receptors and then gives a more detailed account of some recent work on muscle spindles, and especially on the relationship between the different fusimotor effects, the different types of motor ending and the activity of different intra-fusal fibres. There is also useful information about some non-mammalian species.

McIntyre has written a lucid account of the central actions of impulses from muscle afferents, starting with a useful section on methods of selective activation of afferent fibres. By treating each part of the subject in a historical way he builds up a clear picture of the present position and the present problems. This section is brief and somewhat limited in scope, but within these limitations it is excellent.

Hunt gives, therefore, useful information on physiological work of the last year or two and McIntyre provides a section that serves as a valuable introduction to the central actions of muscle afferents; but it is the long section by Barker on anatomy that will make many teachers, research workers and advanced students wish to have this book on their shelves.

Peter M. H. Rack

\section{Combating drought}

Physiological Aspects of Dryland Farming. Edited by U. S. Gupta. (Oxford and IBH: New Delhi, Bombay and Calcutta, 1975.) RS.80.00.

Drought is the major factor limiting world food production and its occurence is inevitable, but its effects may be reduced by developing a dry farming technology based on an understanding of plant-water relationships. Eleven different authors review aspects of this subject, beginning with a detailed consideration of the physiological principles of dryland crop production by Arnon (Israel). There follow reviews of drought injury and resistance of crop plants by Larson (US), root patterns in crop plants by Hurd and Spratt (Canada), the role of mulches by Unger (U.S.A.) and the effects of humidity on crop growth by O'Leary (U.S.A.) and of wind by Sturrock (New Zealand).

As almost all the water taken up by the roots is transpired to the atmosphere by the leaves there is considerable interest in the use of anti-transpirants to reduce water losses from the leaves and this aspect is discussed by Davenport and Hagan (US). As photosynthesis proceeds much dry matter is lost through photorespiration and the biochemistry of this process is described by Goldsworthy (UK), who also speculates on the remote possibility of reducing this loss in the future-either by using chemicals or by the development by plant breeders of a wider range of crops with C-4 metabolism which do not seem to photorespire. Finally, Iwata (Japan) summarises information on the heat unit concept of crop maturity and discusses its application in crop production. Each chapter is supported by a long list of references to published literature for those wishing to probe deeper.

Although the emphasis is on dryland farming the principles discussed apply also to crops grown in more favourable water regimes, and this book has a much wider value to agronomists, crop physiologists, plant physiologists, botanists and ecologists than that suggested by the title.

J. D. Ivins

\section{Fundamentals of neurophysiology}

Fundamentals of Neurophysiology. Edited by Robert F. Schmidt. Pp. ix +293 . (Springer: Heidelberg, Berlin and New York, 1975.) DM29; $\$ 12.50$.

THE cost of most reference physiological textbooks has created a demand for less expensive paperback versions. Unfortunately for those who teach neurophysiology these condensed paperback versions usually give an inadequate account of that subject. Fundamentals of Neurophysiology is a paperback English edition of a German textbook based on a programmed textbook of a series of lectures to first-year physiology students.

The book is divided into eight sections. Those concerned with excitation of nerve and muscle, synaptic transmission and properties of muscle are very good. The sensory system is well presented although there is an inadequate account of the physiology of pain. The sections concerned with reflexes, the motor system and the autonomic nervous system are based on the hypothesis that there is a hierarchical organisation within the nervous system with "higher" and "lower" centres. The higher centres control the lower, and together they somehow mould a great variety of stereotyped reflexes into what we know as movement and posture. This was a very productive hypothesis in the last century but it has been falsified so often in this century that its use in a modern textbook of neurophysiology is questionable.

After each major topic within a section are a series of questions which the reader is advised to answer before proceeding. This method of self assessment, if it is to be successful, requires careful attention to the content and phrasing of both questions and answers. Unhappily in some sections both the questions and some choices given for answers are trivial.

Apart from that and minor points of disagreement which are undoubtedly the result of having to simplify and condense controversial concepts, the authors have written an excellent textbook for most neurophvsiological courses. The text is well written, the illustrations are unambiguous, and a consistent, adequate standard for the medical physiology student is maintained Unfortunately the price will put this book beyond the reach of all but the most affluent student.

T. H. Koeze 